\title{
Optimization of Pressure Parboiling Conditions and Pre-Conditioned Moisture Content of Brown Rice (Unpolished Rice) for Microwave Puffing and its Comparison with Hot Sand Bed Puffing
}

\author{
Ajay Kumar Swarnakar ${ }^{*}$, Prem Prakash Srivastava, And Susanta Kumar Das ${ }^{\mathrm{a}}$ \\ a Agricultural and Food Engineering Department - Indian Institute of Technology Kharagpur - West Bengal, \\ 721302, India \\ ${ }^{*}$ Corresponding author \\ aksw11@gmail.com \\ TEL: $+91-8101766639$
}

Received: 7 April 2018; Published online: 18 January 2020

\begin{abstract}
Brown rice puffing (unpolished rice) gives a more nutritious product compared to traditional puffed polished rice and reduces the cost of the product significantly, even though, the rice bran layer resists expansion during puffing. In the present study, brown rice was puffed in a microwave and hot-sand-bed after its pressure parboiling. Pressure parboiling parameters, steam pressure $(196,294,392,490 \mathrm{kPa})$ and steaming time $(5,10,15 \mathrm{~min})$, along with pre-conditioned moisture content $(8,10,12 \% \mathrm{wb})$ were studied and optimized for puffing characteristics (puffing percentage, expansion ratio, whiteness index, bulk density and hardness). All the experiments were carried out using a full factorial design. Statistical analysis showed there was a significant effect of processing variables on puffing characteristics. Optimized steam pressure, steaming time and pre-conditioned moisture content for microwave puffing were found to be $303.6 \mathrm{kPa}, 14.25 \mathrm{~min}$ and $11.6 \%$ (wb) respectively, and for hot-sand-bed puffing to be $260.7 \mathrm{kPa}, 15 \mathrm{~min}$ and $8 \%(\mathrm{wb})$ respectively.
\end{abstract}

Keywords: Brown rice puffing; Cereal puffing; Microwave puffing; Hot-sand-bed puffing; Pressure parboiling

\section{Introduction}

In the modern lifestyle, consumers are looking for nutritious products that are easily accessible and conveniently prepared. Bulk handling and storage of puffed rice is inconvenient for vendors and families who prefer fresh puffed rice. During long periods of storage, puffed rice losses its crispiness, which is one of the most important sensory qualities of any puffed product, due to moisture absorption. Thus, microwave puffing of pre-packed, pre-conditioned brown rice provides a good option for obtaining a nutritious, hygienic and convenient product to meet the needs of this group of consumers on the go.

Puffed rice is a popular and traditional snack food in Southeast Asia. It is produced from parboiled polished rice by roasting it on an agitated hot-sand-bed at around $250{ }^{\circ} \mathrm{C}$ for 10 to $12 \mathrm{~s}$. Other commercial puffing processes for rice are hot air puffing, gun puffing and oil puffing. However, microwave puffing is a recent development in this aspect (Maisont \& Narkrugsa, 2009).

Puffed unpolished rice is receiving more interest than puffed polished parboiled rice because of the excellent health beneficial properties of the bran 


\begin{tabular}{|llll|}
\hline \multicolumn{2}{|l}{ Nomenclature } & & \\
& & & \\
$\mathrm{P}$ & Steam pressure, $\mathrm{kPa}$ & ER & Expansion ratio \\
$\mathrm{T}$ & Steaming time, min & WI & Whiteness index \\
M & Pre-conditioned brown rice moisture & BD & Bulk density, $\mathrm{kg} / \mathrm{m}^{3}$ \\
& content, \% (wb) & Hd & Hardness, N \\
PP & Puffing percentage & D & Desirability \\
& & & \\
\hline
\end{tabular}

(Mir, Bosco, Shah, \& Mir, 2016; Swarnakar, Srivastav, \& Das, 2019). Rice bran is a good source of vitamins, minerals, fibre, protein and fat (Gul, Yousuf, Singh, Singh, \& Wani, 2015). Polishing removes most of these nutrients and the extent of removal is proportional to the degree of polishing (Lamberts et al., 2007). It is pertinent to mention that, polishing is the most energy intensive step in the whole rice milling operation (Mohapatra \& Bal, 2007), utilising approximately $43 \%$ of the total energy input (Ekasilp, Soponronnarit, $\&$ Therdyothin, 1995). Thus, puffing of brown rice could be economically beneficial if the quality of the product meets both the nutritional and organoleptic requirements of the consumers. Earlier efforts to puff brown rice using hot air were not satisfactory in terms of product quality (Chandrasekhar, 1989). With this present background, production of puffed rice from parboiled brown rice with acceptable quality attributes is a challenge.

The expansion ratio is a highly important quality parameter for any puffed product. Earlier studies show that expansion increased with an increase in the degree of gelatinization of native starch but decreased with starch retrogradation (Chinnaswamy \& Bhattacharya, 1986; Mahanta \& Bhattacharya, 2010). Pressure parboiling can gelatinise rice up to the centre, with less retrogradation (Ali \& Bhattacharya, 1982). In the normal parboiling process, paddy is soaked for a few hours in water at $70{ }^{\circ} \mathrm{C}$ followed by steaming with moderate pressure steam (Bhattacharya, 2011). It requires a long time to com- plete the process. In the pressure parboiling process, partially soaked paddy is treated with pressurised steam (Ali \& Bhattacharya, 1982). Compared to the normal parboiling process, pressure parboiling is a relatively quick process (Agidi, Dauda, \& Igbeka, 2008; Roy et al., 2008).

In this study, puffing of pressure parboiled brown rice using microwave energy was chosen for convenience and hygienic reasons. The product quality was compared with that of the conventional process using hot-sand-bed puffing. Chandrasekhar (1989) has reported that about $0.6 \%$ $(\mathrm{w} / \mathrm{w})$ of sand particles adhere on the surface of puffed rice in hot sand bed puffing. Several studies have been reported on microwave puffing of cereals (Maisont \& Narkrugsa, 2009; Mishra, Joshi, Mohapatra, \& Babu, 2015; Swarnakar, Kalpana Devi, \& K. Das, 2014). Thus, present work aimed to investigate the effect and optimize the parboiling pressure, time and preconditioned moisture content of brown rice for its puffing in the microwave oven and comparision with hot-sand-bed puffing methods.

\section{Materials and Methods}

\subsection{Rice variety}

A high amylose content rice variety (IR 1010) was chosen for this study. Mahanta and Bhattacharya (2010) suggested that a high amylose content rice variety was a better option for puffing. Paddy was procured from the local market in Kharagpur, West Bengal, India. This IR 1010

IJFS | January 2020 | Volume 9 $\mid$ pages SI1-SI16 
Puffing of brown rice $\mid$ SI3

is a slender rice variety, with a length to breadth ratio of $3.4 \pm 0.2$ (International Rice Research Institute, 2013), and its amylose content was estimated as $25.1 \pm 0.4 \%$.

\subsection{Pressure parboiling of paddy}

Parboiling of unhusked raw rice was carried out using steam pressure ranging between 196 and $490 \mathrm{kPa}$. A pressure vessel used in this parboiling process was fabricated. Detailed features of this vessel are shown in Fig. 1. About $2 \mathrm{~kg}$ cleaned paddy was placed inside the perforated vessel (2) and it was allowed to soak in normal tap water in situ for 7 min at ambient temperature and fully submerged conditions. After draining the water, the vessel was then closed. Steam from a highpressure steam generator was allowed to pass through the perforated pipe (8). The desired steam pressure inside the vessel was regulated by operating the vent valves (10). Steaming was continued for the desired duration of time. After the steaming operation, the parboiled paddy was taken out and spread on a tray. Then the tray was put inside a hot air oven at $80{ }^{\circ} \mathrm{C}$ for drying of the paddy. The dried parboiled paddy was dehusked using a laboratory twin rubber roll dehusker (Model THU35A, Satake Engineering, Japan) equipped with an aspiration system for separation of the husk from brown rice. Broken kernels were separated from the whole brown rice using a laboratory rice grader (Burrows, Illinois, USA).

\subsection{Preconditioning of parboiled brown rice}

Pre-conditioning of the brown rice is a vital step. In this step, the desired level of salt (in water solution) was allowed to diffuse slowly into the rice kernels. About $200 \mathrm{~g}$ pressure parboiled brown rice was mixed with the $40 \mathrm{ml}$ salt solution and it was kept for $1 \mathrm{~h}$ at room temperature for equilibration. The final salt content in the rice was maintained at around $3.5 \%(\mathrm{w} / \mathrm{w})$ as described by an earlier study (Minati \& Das, 2011). The salt-infused brown rice was dried in a laboratory fluidized bed dryer (Lab model, Basic Technology, India) at $70^{\circ} \mathrm{C}$ with an air flow rate around
$3 \mathrm{~m} / \mathrm{s}$ (Das, 2013) till the desired moisture content was obtained. The moisture content of the pre-conditioned brown rice was measured using a standard hot air oven method (Official methods of analysis. Association of Official Analytical Chemists, 1990). This process of heating and moisture regulation is called pre-conditioning of rice. The pre-conditioned brown rice was packed in an airtight container and kept for subsequent experiments.

\section{$2.4 \quad$ Puffing of preconditioned brown rice}

Puffing of pre-conditioned brown rice was carried out using a domestic microwave oven (Model: M197DL, SAMSUNG, India) and hot-sand-bed roasting for comparison. In microwave puffing, about $10 \mathrm{~g}$ pre-conditioned brown rice was packed in a paper envelope $(245 \times 100 \mathrm{~mm})$ and sealed with adhesive tape. The packet was placed at the center of the turn-table of a 28-liter capacity domestic microwave oven. It was set for 35 $\mathrm{s}$ heating at its maximum output power level of $1000 \mathrm{~W}$.

Hot-sand-bed puffing was carried out in batches using a hemispherical round bottom metal vessel containing coarse grade sand. The sand was heated at the bottom of vessel and grain was put into it with continuous agitation for uniform distribution of heat and proper heat transfer. Generally, the ratio of sand to rice was about 10:1. The grains were dropped on to the sand-bed when its temperature reached around $210-240{ }^{\circ} \mathrm{C}$ (Smita, 2008). After the completion of puffing, the puffed grains were removed from the sand bed, and a fresh batch of grain was dropped and puffed similarly. A small number of fine sand particles normally remained loosely adhered at the surface of the puffed rice. These sand particles were separated using a sieve and returned to the vessel.

\subsection{Puffing characteristic of puffed brown rice}

The puffing percentage (PP) and the expansion ratio (ER) were determined by using eqs. 1 and 2, respectively (Minati \& Das, 2011). Puffing 
SI4 | Swarnakar et al.

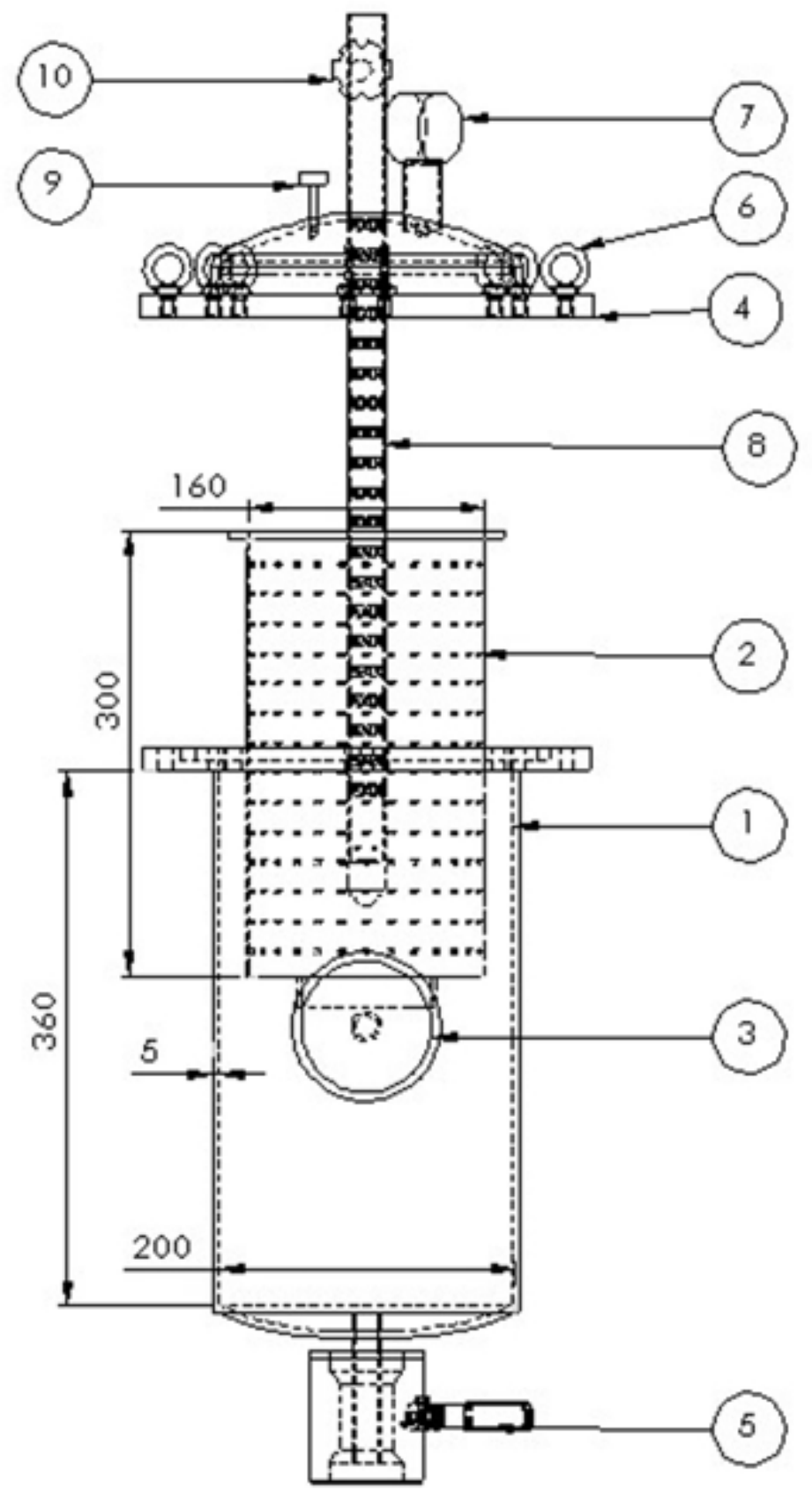

All dimensions in $\mathrm{mm}$

Figure 1: Front views of the pressure parboiling system - (1) Outer shell (2) perforated paddy container for holding paddy (3) dial thermometer (4) closer ring (5) steam condensate outlet (6) lid tightening bolt (7) pressure gauge (8) perforated pipe for steam distribution in paddy bed (9) safety valve (10) steam inlet pipe with vent valve 
percentage is the ratio of the number of puffed rice (NP) to the total number of rice initially taken $\left(\mathrm{N}_{i}\right)$. Thus, mathematically it is

$$
P P=\frac{N_{p}}{N_{i}} \times 100
$$

The expansion ratio is the ratio of the volume of the puffed rice to the volume of the initial rice. In order to obtain the volume of puffed rice, a sand displacement method was used as described by Minati and Das (2011). Puffed rice was poured into a graduated glass measuring cylinder. The voids in that bed were filled with clean (all organic materials removed by acid and alkali treatment) and completely dry fine sand with tapping, and the total volume was measured $\left(\mathrm{V}_{t}\right)$. This was followed by separation of sand and the puffed rice by a shaking-screen. After separating the sand from the puffed rice, the volume of sand was measured again. This is a void volume $\left(\mathrm{V}_{v}\right)$. The difference $\left(\mathrm{V}_{t}-\mathrm{V}_{v}\right)$ is the volume of the puffed rice. The volume of rice before puffing $\left(\mathrm{V}_{i}\right)$ was measured by the same methodology. Thus, mathematically, ER is expressed as

$$
E R=\frac{V_{t}-V_{v}}{V_{i}}
$$

The quality of the puffed brown rice, viz., colour, bulk density (BD) and hardness (Hd) were measured as follows. Colour was measured in the L, $\mathrm{a}$ and $\mathrm{b}$ Hunter colour coordinate system using a Croma Meter (CR-400, Konica Minolta, Japan). Whiteness index (WI), a derived parameter, was estimated using eq. 3 following the methodology described by (Hsu, Chen, Weng, \& Tseng, 2003). Three readings were taken and then averaged.

$$
W I=100-\sqrt{(100-L)^{2}+a^{2}+b^{2}}
$$

Bulk density of puffed brown rice samples was estimated from the weight and corresponding bulk volume of the puffed rice. A known weight of puffed rice was placed in a graduated measuring cylinder, and after gently tapping ten times on the counter top, the volume was noted (Mariotti, Alamprese, Pagani, \& Lucisano, 2006). The mean of three measurements was recorded.

Hardness of the puffed rice samples was measured using a texture analyser (TA-XT2i, Stable Microsystem, UK), with a probe diameter of $25 \mathrm{~mm}, 25 \mathrm{~kg}$ load cell and $10 \mathrm{~mm} / \mathrm{s}$ cross head speed (Nath, Chattopadhyay, \& Majumdar, 2007). The mean value of six readings for each of the samples was recorded.

\subsection{Experimental design and optimization}

The experiments were designed according to full factorial design on four levels of parboiling steam pressure $(196,294,392,490 \mathrm{kPa})$, three levels of steaming time $(5,10,15 \mathrm{~min})$ and three levels of pre-conditioned brown rice moisture content $(8$, $10,12 \% \mathrm{wb})$. Table 1 shows the details of these independent variables along with dependent variables. In order to visualize the effect of independent parameters $(\mathrm{X})$ on the dependent parameters $(\mathrm{Y})$ the following eq. 4 was used.

$$
\begin{aligned}
Y= & b_{0}+b_{1} X_{1}+\ldots+b_{12} X_{1} X_{2}+b_{1} 3 X_{1} X_{3}+\ldots \\
& +b_{23} X_{2} X_{3}+b_{11} X_{1}^{2}+b_{22} X_{2}^{2} \ldots+\xi
\end{aligned}
$$

Where $b_{o}$ (constant term) $b_{1}, b_{2}, \ldots$ (linear effect) $b_{12}, b_{13}, \ldots$ (interaction effect) $b_{11}, b_{22}, \ldots$ (quadratic effect) are the coefficients and $\xi$ is the random error associated with them.

\section{Statistical analysis:}

The significance of all the terms in the regression equation was evaluated by analysis of variance (ANOVA). The adequacy of a regression equation was checked by the $\mathrm{R}^{2}$ (coefficient of determination), adjusted $\mathrm{R}^{2}$, predicted $\mathrm{R}^{2}$, model $\mathrm{p}$-value, adequacy precision value and coefficient of variation (CV\%) (Giri \& Prasad, 2007; Mohapatra \& Bal, 2007). Regression equations of the dependent variables were obtained after rejecting the non-significant terms at the $95 \%$ confidence level $(\mathrm{p}<0.05)$. Response surfaces between dependent and independent variables were produced after keeping the third independent variable at its centre level.

An ANOVA table of each regression equation coefficients was also generated by Design Expert software (Design Expert, version 7. 0. 0, StatEase INC., 2009, USA) to determine the effect on the dependent variables. The significance of

\begin{tabular}{l|l|l|l} 
IJFS & January 2020 & Volume 9 & pages SI1-SI16
\end{tabular} 
Table 1: Independent and dependent variables used in puffing of brown rice

\begin{tabular}{lll}
\hline Independent variables $(\mathrm{X})$ & Levels & Dependent variables $(\mathrm{Y})$ \\
\hline $\begin{array}{l}\text { Steam pressure }(\mathrm{P}), \mathrm{kPa} \\
\text { (gauge pressure) }\end{array}$ & $196,294,392,490$ & $\begin{array}{l}\text { Puffing percentage }(\mathrm{PP}) \\
\text { (for microwave puffing }\end{array}$ \\
$\begin{array}{l}\text { Steaming time }(\mathrm{T}), \mathrm{min} \\
\text { only), Expansion ratio } \\
(\mathrm{ER}), \text { Whiteness index }(\mathrm{WI}),\end{array}$ \\
$\begin{array}{l}\text { Pre-conditioned brown rice } \\
\text { moisture content }(\mathrm{M}), \% \mathrm{wb}\end{array}$ & $8,10,15$ & $\begin{array}{l}\text { Bulk density (BD), kg } / \mathrm{m} 3, \\
\text { and Hardness }(\mathrm{Hd}), \mathrm{N}\end{array}$ \\
\hline
\end{tabular}

all the terms of independent variables in the regression equation was judged statistically at $95 \%$ confidence interval $(\mathrm{p}<0.05)$.

\section{Optimization:}

Numerical optimization was carried out for optimizing processing variables in software (Design Expert, version 7. 0. 0, Stat-Ease INC., 2009, USA). Optimum condition was selected on the basis of higher overall desirability (D) value (eq. 5). $\mathrm{D}$ is a function of the individual desirability $\left(\mathrm{d}_{i}\right)$ of each variable that varies between 0 and 1 (Montgomery, 2017).

$$
D=\left[d_{1}\left(y_{1}\right) \times d_{2}\left(y_{2}\right) \ldots \times d_{k}\left(y_{k}\right)\right]^{(1 / k)}
$$

In this equation, $\mathrm{k}$ denotes the number of variables. All independent variables were kept in the range while dependent variables $\mathrm{PP}, \mathrm{ER}$ and WI were maximized and those of $\mathrm{BD}$ and $\mathrm{Hd}$ were minimized.

\section{Results and Discussion}

\subsection{Model accuracy}

Regression models obtained for responses in the microwave and hot-sand-bed puffing are shown in Table 3. Positive and negative terms of the models explain the positive and negative effect of processing variables on quality characteristics, respectively. Quadratic terms of processing variables showing its effect on quality characteristics are curvilinear. The factors that were insignificant $(\mathrm{p}>0.05)$ were excluded from the models without affecting the models' hierarchy. It is inferred from Table 3 that all the regression models were found to be statistically significant at the $99.99 \%$ confidence level. The coefficient of variation of all the models except $\mathrm{BD}$ and $\mathrm{Hd}$ were found closer to 10 which indicates a good fit of the models (Giri \& Prasad, 2007). All the models showed good fits with more than four adequate precision values, reasonable $\mathrm{R}^{2}$ value and difference less than two between adjusted $\mathrm{R}^{2}$ and predicted $\mathrm{R}^{2}$. Thus, these models can be used for prediction of quality characteristics of puffed brown rice in microwave and hot-sand-bed puffing.

\subsection{Puffing characteristic of pressure parboiled puffed brown rice}

\section{Puffing percentage}

The effect of steaming pressure, time and preconditioned brown rice moisture content on $\mathrm{PP}$ during microwave heating is shown in Fig. 2. Parboiling at $196 \mathrm{kPa}$ for 5 min was not found to be suitable for brown rice puffing. A white belly or ungelatinized core was observed in the brown rice which was due to the incomplete gelatinization of rice starch as mentioned by Ali and Bhattacharya (1982). Gelatinisation is the primary criteria for puffing of rice as it seals the cracks in grains and hardens the rice kernel which acts like a pressure vessel during puffing (van der Sman \& Bows, 2017). In ungelatinised rice, during the puffing process in presence of moisture, rice starch undergoes a gelatinisation process and reduces the amount of moisture to create a proper vapour pressure for expansion (Gulati \& Datta, 2016). Thus, increasing the pressure and 
Puffing of brown rice $\mid$ SI7

time up to $400 \mathrm{kPa}$ and $12 \mathrm{~min}$, respectively, increases the extent of gelatinisation which in turn has a positive effect on PP. Further increases in both of these variables leads to an increase in starch retrogradation and a negative impact on puffing (Chinnaswamy \& Bhattacharya, 1986). This may be due to the fact that after $400 \mathrm{kPa}$ and 12 min of rice steaming there was an adverse effect on PP (Fig. 2 a). Pre-conditioned brown rice moisture content has a positive but less significant $(\mathrm{p}<0.05)$ effect on $\mathrm{PP}$ as compared to the other processing variables (Fig. $2 \mathrm{~b}$ and Table 2 ). The $\mathrm{F}$ value of pre-conditioned moisture content's linear term was least among all the terms of processing variables.

Brown rice produced at $196 \mathrm{kPa}$ with $5 \mathrm{~min}$ steaming did not puff in a hot-sand-bed $(0 \% \mathrm{PP})$ as observed in microwave puffing. Brown rice produced at a higher steaming pressure and time than $196 \mathrm{kPa}$ with 5 min showed $100 \%$ puffing in the hot-sand-bed. The hot-sand-bed provides a preheated medium for puffing of rice, which might help to generate sudden puffing vapour pressure inside the grain. This process helps with the puffing of rice. Sharma and Gujral (2011) also reported, sand bed roasting of barley showed a greater puffing index than with microwave roasting. Joshi, Mohapatra, Joshi, and Sutar (2014) also observed similar results during the puffing of rice in a preheated microwave oven at a different power level. Thus, the rapid or preheated medium in grain increases the magnitude of puffing.

\section{Expansion ratio}

The effect of processing variables on ER in microwave and hot-sand-bed puffing showed similar trends as depicted in Fig. 3. The expansion ratio of puffed brown rice gradually increased with the increasing processing variables as the linear terms of processing variables were found significant $(\mathrm{p}<0.01)$ (Table 2). Parboiling pressure had a significantly higher effect $(\mathrm{p}<0.001)$ on ER of microwave puffed brown rice than hotsand-bed puffed brown rice. On the other hand, steaming time showed more effect $(p<0.001)$ on ER of hot-sand-bed puffed brown rice. These results for hot-sand-bed puffing agree with the findings of Chinnaswamy and Bhattacharya (1986) and Mahanta and Bhattacharya (2010). Moreover, the interaction terms of steaming pressure and time were found to have the most significant effect, as evident by the highest $\mathrm{F}$ values for both the puffing methods (Table 2). Gelatinisation increases gradually with steaming pressure and time (Ali \& Bhattacharya, 1982), which increases the ER of puffed brown rice. Gelatinization of starch is a primary criterion for the puffing as previously mentioned and reported in several studies (Chandrasekhar \& Chattopadhyay, 1991; Chinnaswamy \& Bhattacharya, 1986; Mahanta \& Bhattacharya, 2010; Moraru \& Kokini, 2006). Excessive increase in the parboiling pressure was shown to have an adverse effect on the expansion of puffed brown rice (Fig. 3). The ER decreased in hot-sand-bed puffing beyond 400 $\mathrm{kPa}$ steam pressure whereas it showed a constant trend in the case of microwave puffing. Thus, the response surface of the ER with the processing variable was curvilinear (Fig. 3) and it followed a quadratic relationship (Table 3 ). The probable reason could be retrogradation of starch as previously discussed. In hot-sand-bed puffing, the effect of the quadratic term of steam pressure was greater in comparison to its linear term (Table 2). Chandrasekhar and Chattopadhyay (1991) also observed similar results with severe parboiling conditions during hot air puffing of rice. The ER of hot-sand-bed puffed brown rice was found to be less than the microwave puffed brown rice for $5 \mathrm{~min}$ steaming. However, the effect of steaming time on ER in hot-sand-bed puffing was more than in microwave puffing. This might be as a result of the preheated sand bed temperature helping in the expansion. Due to the preheated puffing medium, pre-conditioned brown rice moisture content was more effective in the hot-sand-bed puffing. The pre-conditioned moisture content of brown rice had an adverse effect on ER. Its effect was less than steaming time and pressure (Table 2). An increase in the moisture content decreases the glass transition temperature. These conditions produce less vapor pressure inside the rice kernel because the soft or rubbery stage of rice occurs at low temperature (Shimoni, Dirks, \& Labuza, 2002) which is an important stage of the rice puffing process. Simultaneously, a high moisture content requires more energy to produce a high vapour pressure

\begin{tabular}{l|l|l|l} 
IJFS & January 2020 & Volume 9 & pages SI1-SI16
\end{tabular} 


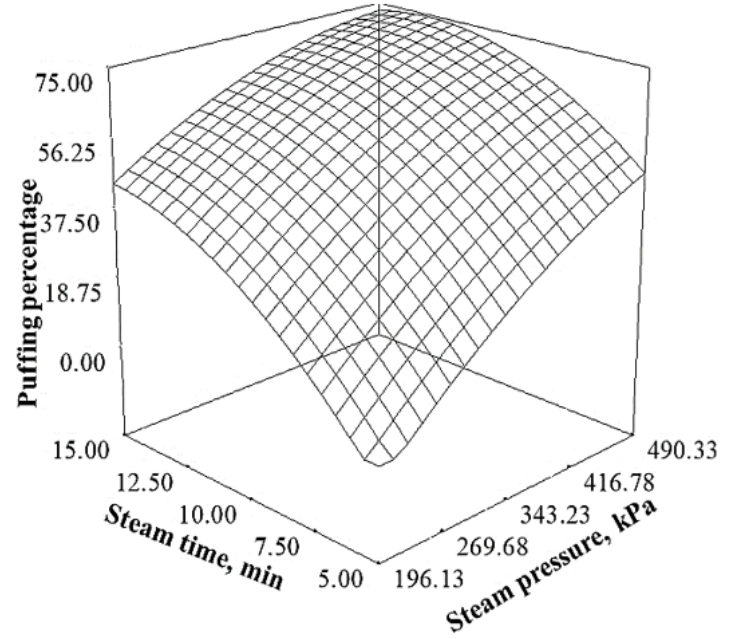

(a)

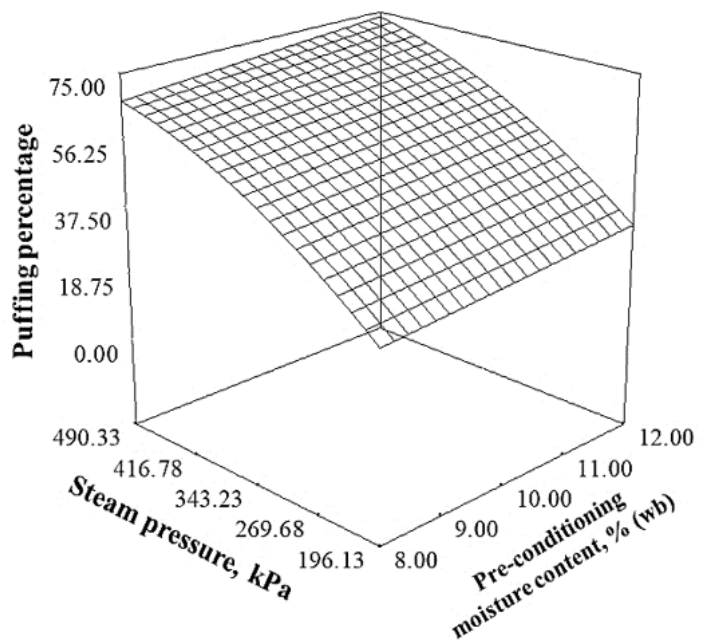

(b)

Figure 2: Puffing percentage of puffed brown rice with microwave heating under varied levels of steam pressure and steam time, and pre-conditioned brown rice moisture content

Table 2: ANOVA for the variables of linear, quadratic and interaction terms on each response

\begin{tabular}{|c|c|c|c|c|c|c|c|c|c|}
\hline \multirow{3}{*}{$\begin{array}{l}\text { Variable/ } \\
\text { Factor }\end{array}$} & \multicolumn{9}{|c|}{ F - value } \\
\hline & $\mathrm{PP}$ & ER & & WI & & BD & & $\mathrm{Hd}$ & \\
\hline & MW & MW & HSB & MW & HSB & MW & HSB & MW & HSB \\
\hline Model & $57.48^{* * *}$ & $49.28^{* * *}$ & $53.72^{* * *}$ & $20.42^{* * *}$ & $7.82^{* * *}$ & $7.52^{* * *}$ & $21.27^{* * *}$ & $12.20^{* * *}$ & $13.60^{* * *}$ \\
\hline $\mathrm{P}$ & $227.57^{* * *}$ & $104.95^{* * *}$ & $29.53^{* * *}$ & $47.10^{* * *}$ & $31.77^{* * *}$ & $16.58^{* * *}$ & $52.66^{* * *}$ & $40.06^{* * *}$ & $38.99^{* * *}$ \\
\hline $\mathrm{T}$ & $236.52^{* * *}$ & $69.75^{* * *}$ & $230.22^{* * *}$ & $11.03^{* *}$ & $0.54^{n s}$ & $13.89^{* * *}$ & $48.21^{* * *}$ & $25.87^{* * *}$ & $29.18^{* * *}$ \\
\hline M & $6.10^{*}$ & $9.72^{* *}$ & $15.62^{* * *}$ & $3.13^{n s}$ & $0.74^{n s}$ & $0.37^{n s}$ & $11.63^{* *}$ & $0.94^{n s}$ & $0.13^{n s}$ \\
\hline $\mathrm{P} \times \mathrm{T}$ & $14.13^{* * *}$ & $191.99^{* * *}$ & $122.21^{* * *}$ & - & $11.47^{* *}$ & $21.55^{* * *}$ & $38.57^{* * *}$ & $30.41^{* * *}$ & $35.16^{* * *}$ \\
\hline $\mathrm{P} \times \mathrm{M}$ & $0.026^{n s}$ & $0.093^{n s}$ & $3.119 \times 10-3^{n s}$ & - & $0.94^{n s}$ & $0.2^{n s}$ & $0.30^{n s}$ & $1.54^{n s}$ & $0.042^{n s}$ \\
\hline $\mathrm{T} \times \mathrm{M}$ & $0.025^{n s}$ & $1.32^{n s}$ & $2.33^{n s}$ & - & $1.45^{n s}$ & $0.14^{n s}$ & $0.14^{n s}$ & $0.60^{n s}$ & 0.35 \\
\hline $\mathrm{P}^{2}$ & $6.81^{*}$ & $60.28 * * *$ & $81.82^{* * *}$ & - & - & $11.33^{* *}$ & $31.19^{* * *}$ & $6.67^{*}$ & $8.70^{* *}$ \\
\hline $\mathrm{T}^{2}$ & $24.12^{* * *}$ & $4.99^{* *}$ & $1.25^{n s}$ & - & - & $3.62^{n s}$ & $8.76^{* *}$ & $2.66^{n s}$ & $8.57^{* *}$ \\
\hline $\mathrm{M}^{2}$ & $2.07^{n s}$ & $0.49^{n s}$ & $0.49^{n s}$ & - & - & $0.014^{n s}$ & $0.020^{n s}$ & $1.05^{n s}$ & $1.3^{n s}$ \\
\hline
\end{tabular}

MW - Microwave puffing, HSB - Hot-sand-bed puffing

$\mathrm{P}$ - Parboiling steam pressure (kPa), T - Parboiling steaming time (min), M - Pre-conditioned brown rice moisture content $(\%, \mathrm{wb})$

PP - Puffing percentage, ER - Expansion ratio, WI - Whiteness index, BD - Bulk density $\left(\mathrm{kg} / \mathrm{m}^{3}\right)$,

$\mathrm{Hd}$ - Hardness (N) 
Puffing of brown rice $\mid$ SI9

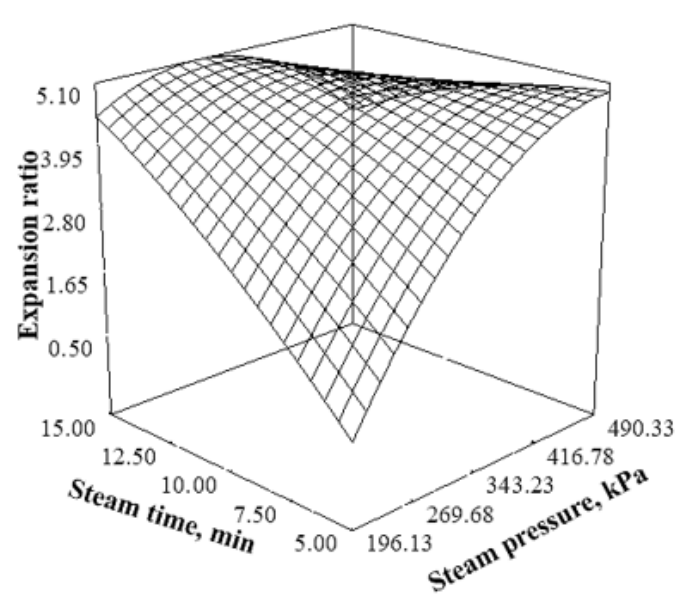

(a)

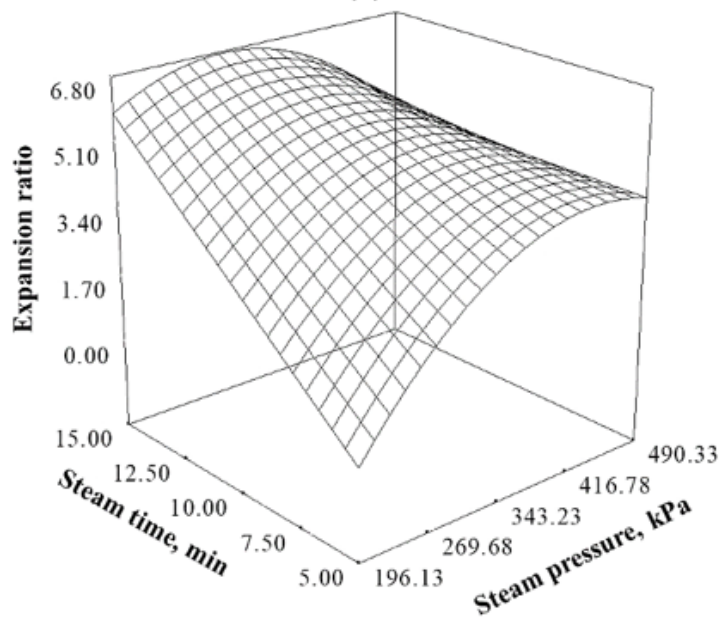

(c)

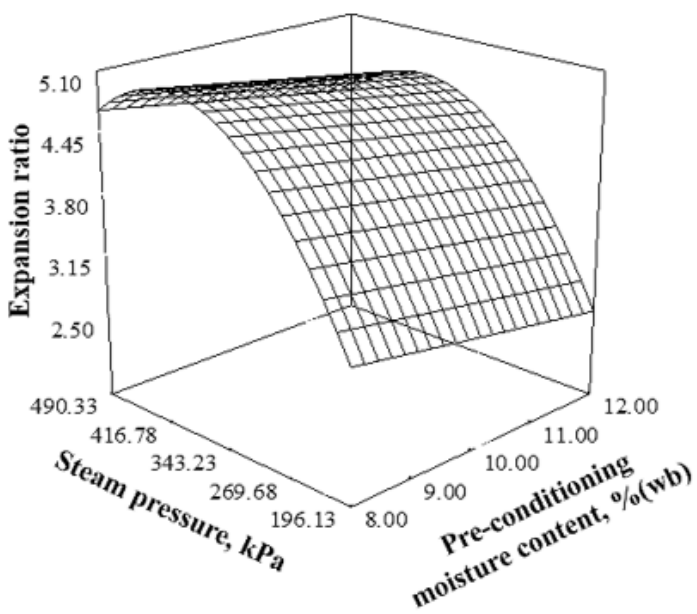

(b)

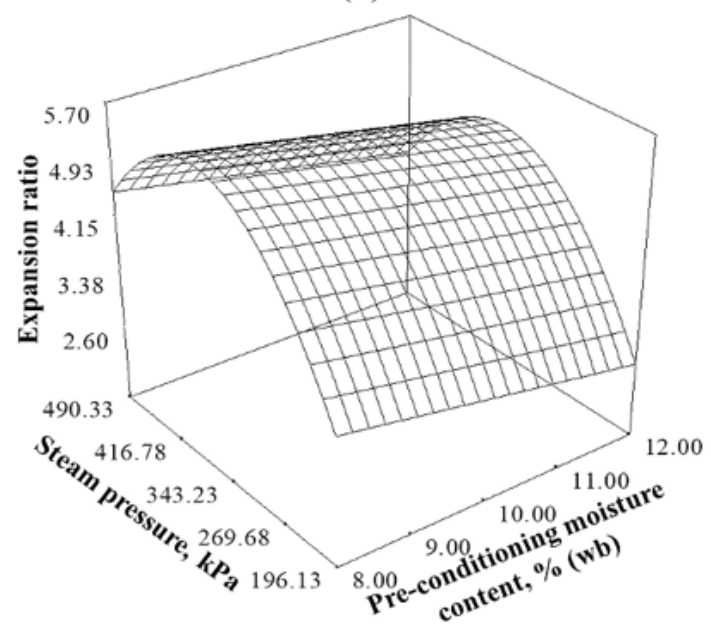

(d)

Figure 3: Expansion ratio of puffed brown rice under varied levels of steam pressure, time and preconditioned brown rice moisture content; ( $\&$ b) microwave puffing, (c \& d) hot-sand-bed puffing 
(Gulati \& Datta, 2016). Thus, an increase in pre-conditioned moisture content decreases the ER of puffed brown rice.

\section{Whiteness Index}

Whiteness index of puffed brown rice was observed to decrease linearly with increasing steam pressure $(p<0.001)$ for both microwave and hotsand-bed puffing (Fig. 4 a and c). Steaming time was observed to have a negative effect on WI in both puffing methods (Fig. 4 a and c) but it was significant $(\mathrm{p}<0.001)$ in case of microwave puffing only (Table 2). However, WI was observed to be independent of pre-conditioned brown rice moisture content $(\mathrm{p}>0.05)$ (Table 2$)$ in both the puffing methods. Steam pressure was found to have more effect on WI of puffed brown rice than steaming time as indicated by $\mathrm{F}$ - values, which were 47.10 and 31.77 for microwave and hot-sand-bed puffing, respectively (Table 2). Parboiling steam pressure has more influence on the discoloration of parboiled rice than steaming time (Bhattacharya, 1996). The parboiling process increases the diffusion of water-soluble husk pigments in rice kernels and simultaneously the Maillard reaction which results in browning of rice kernels as reported by several researchers (Ali \& Bhattacharya, 1982; Bhattacharya, 2011; Lamberts, Brijs, Mohamed, Verhelst, \& Delcour, 2006; Lamberts, Rombouts, Brijs, Gebruers, \& Delcour, 2008). These reactions during the parboiling process were responsible for the low WI of puffed brown rice at higher steaming pressure and time. Chinnaswamy and Bhattacharya (1986) and (Chandrasekhar, 1989) also observed discoloration of puffed rice prepared from high parboiling steaming pressure and time. Thus, the whiteness of puffed brown rice depends on the parboiling conditions as observed in this study.

\section{Bulk density}

Figure 5 represents the effects of parboiling steam pressure, steaming time and preconditioned brown rice moisture content on the $\mathrm{BD}$ of microwave and hot-sand-bed puffed brown rice. Parboiling at $196 \mathrm{kPa}$ for $5 \mathrm{~min}$ steaming produces higher $\mathrm{BD}$ than the other parboiling conditions as observed by the poor expan- sion of puffed brown rice. Bulk density of puffed brown rice decreased as parboiling steam pressure $(\mathrm{p}<0.001)$ increased from $196 \mathrm{kPa}$ to 350 $\mathrm{kPa}$. The BD showed a decreasing trend for microwave puffed brown rice with steaming time ( $\mathrm{p}$ $<0.001$ ) (Fig. 5 a). On the other hand, in hotsand-bed puffing after $10 \mathrm{~min}$ of parboiling $\mathrm{BD}$ there was an increasing trend $(\mathrm{p}<0.01)$ (Fig. 5 c). Thus, the behaviour of $\mathrm{BD}$ with processing variables was curvilinear (Fig. 5) and followed a quadratic order relationship (Table 3). Parboiling steam pressure was observed to have the most significant effect on BD of puffed brown rice of all the processing parameters (Table 2). Pre-conditioned brown rice moisture content was observed to have a significant $(p<0.01)$ effect on BD only in hot-sand-bed puffing and showed a positive relationship (Table 3 ). From the F - values (Table 2) it was also observed that all the processing parameters showed more effect in hot-sand-bed puffing than in microwave puffing. These changes may be due to the high expansion in puffed brown rice at above-mentioned parboiling conditions.

\section{Hardness}

The effect of parboiling steaming pressure, time and pre-conditioned moisture content of brown rice on puffed brown rice Hd is shown in Fig. 6 . Hardness of puffed brown rice decreased significantly $(\mathrm{p}<0.001)$ as steam pressure increases to $350 \mathrm{kPa}$ in both puffing methods. Steaming time significantly $(\mathrm{p}<0.001)$ reduced the $\mathrm{Hd}$ of puffed brown rice but after $10 \mathrm{~min}$ it was increased $(\mathrm{p}<0.01)$ in the hot-sand-bed puffing. At lower steaming pressure and time, the Hd of puffed brown rice was related to less expansion. The influence of pre-conditioned brown rice moisture content was insignificant $(\mathrm{p}>0.05)$ for $\mathrm{Hd}$ of puffed brown rice. The effect of moisture content was less on the expansion of puffed brown rice (Table 2) which may influence the Hd of the puffed grain. Chandrasekhar (1989) and Maisont and Narkrugsa (2010) also observed greater Hd in less expanded puffed rice. Less expanded puffed rice produces small air cells which give compactness to the grain and increases the Hd. 
Puffing of brown rice $\mid$ SI11

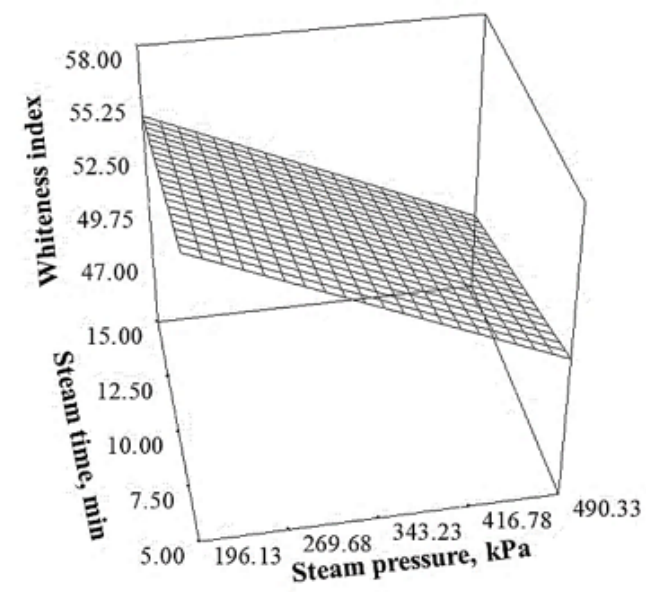

(a)

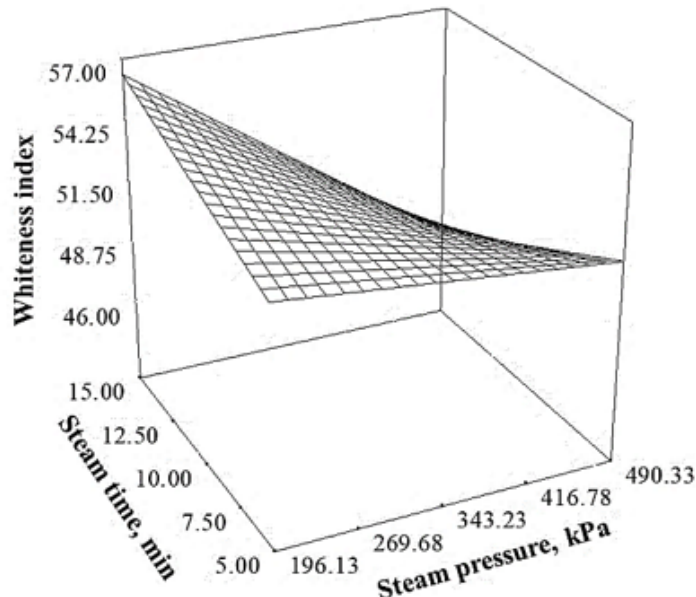

(c)

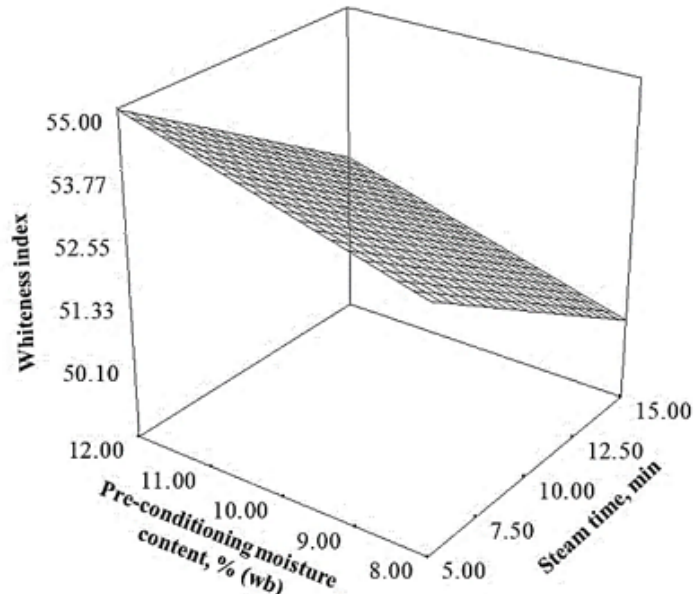

(b)

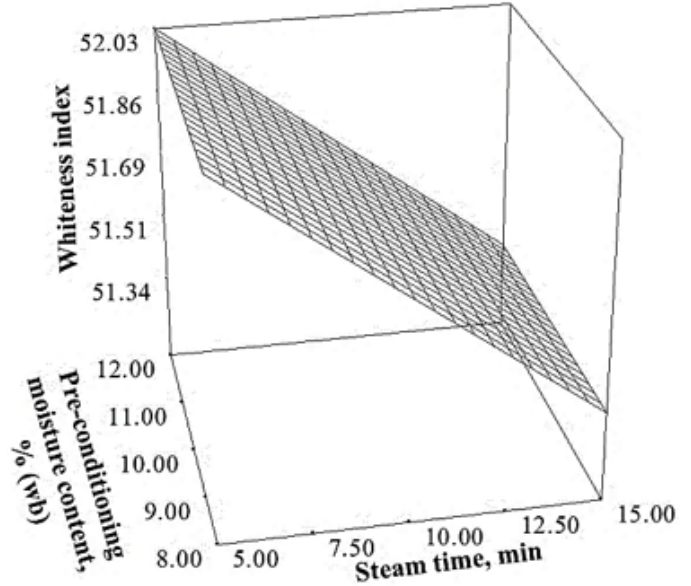

(d)

Figure 4: Whiteness index of puffed brown rice under varied levels of steam pressure, time, and preconditioned brown rice moisture content; ( $\&$ b) microwave puffing, (c \& d) hot-sand-bed puffing 
SI12 | Swarnakar et al.

Table 3: Regression equations of quality characteristics of puffed brown rice with independent variables

\begin{tabular}{|c|c|c|c|c|c|c|}
\hline $\begin{array}{l}\text { Puffing } \\
\text { method }\end{array}$ & Equation & $\mathrm{R}^{2}$ & $\begin{array}{l}\text { Predicted } \\
\mathrm{R}^{2}\end{array}$ & $\begin{array}{l}\text { Adjusted } \\
\mathrm{R}^{2}\end{array}$ & $\begin{array}{l}\text { Adequate } \\
\text { precision }\end{array}$ & $\mathrm{CV} \%$ \\
\hline \multirow{3}{*}{ MW } & $\mathrm{ER}=-10.7738+0.058 \times \mathrm{P}+1.001 \times \mathrm{T}-0.116 \times \mathrm{M}-0.00188 \times \mathrm{P} \times \mathrm{T}-0.000049 \times \mathrm{P}^{2}-0.011 \times \mathrm{T}^{2}$ & 0.940 & 0.904 & 0.928 & 32.039 & 9.15 \\
\hline & $\mathrm{BD}=1350.336-4.567 \times \mathrm{P}-53.607 \times \mathrm{T}+0.124 \times \mathrm{P} \times \mathrm{T}+0.0042 \times \mathrm{P}^{2}$ & 0.676 & 0.539 & 0.634 & 13.411 & 32.68 \\
\hline & $\mathrm{Hd}=174.633-0.548 \times \mathrm{P}-8.208 \times \mathrm{T}+0.0184 \times \mathrm{P} \times \mathrm{T}+0.0000403 \times \mathrm{P}^{2}$ & 0.7586 & 0.629 & 0.727 & 15.381 & 45.57 \\
\hline \multirow{2}{*}{ HSB } & $\mathrm{ER}=-12.664+0.074 \times \mathrm{P}+0.964 \times \mathrm{T}-0.191 \times \mathrm{M}-0.0019 \times \mathrm{P} \times \mathrm{T}-0.0000744 \times \mathrm{P}^{2}$ & 0.941 & 0.920 & 0.931 & 38.336 & 11.09 \\
\hline & $\mathrm{Hd}=90.965-0.227 \times \mathrm{P}-6.146 \times \mathrm{T}+0.00751 \times \mathrm{P} \times \mathrm{T}+0.000174 \times \mathrm{P}^{2}+0.140 \times \mathrm{T}^{2}$ & 0.812 & 0.711 & 0.781 & 16.801 & 19.92 \\
\hline
\end{tabular}

PP - Puffing percentage, ER - Expansion ratio, WI - Whiteness index, BD - Bulk density $\left(\mathrm{kg} / \mathrm{m}^{3}\right), \mathrm{Hd}-$ Hardness $(\mathrm{N})$

$\mathrm{P}$ - Parboiling steam pressure $(\mathrm{kPa}), \mathrm{T}$ - Parboiling steaming time ( $\mathrm{min}), \mathrm{M}$ - Pre-conditioned brown rice moisture content $(\%$, wb)

MW - Microwave puffing, HSB - Hot-sand-bed puffing

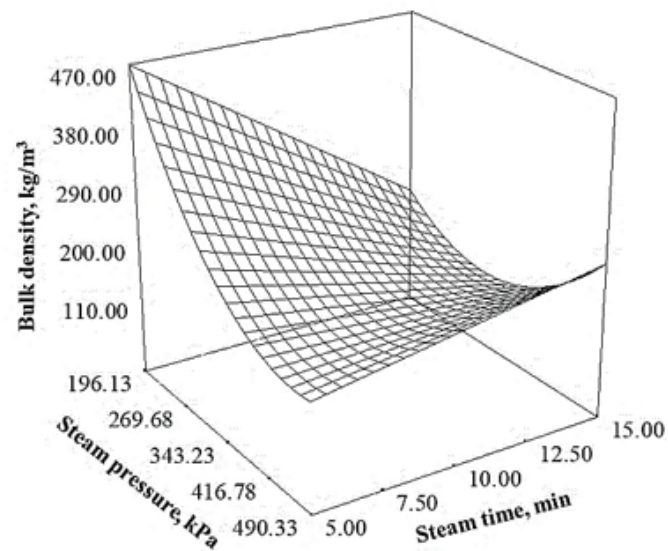

(a)

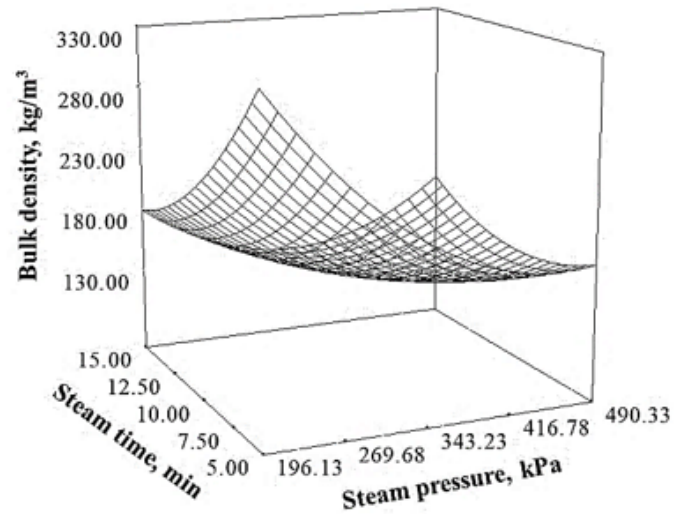

(c)

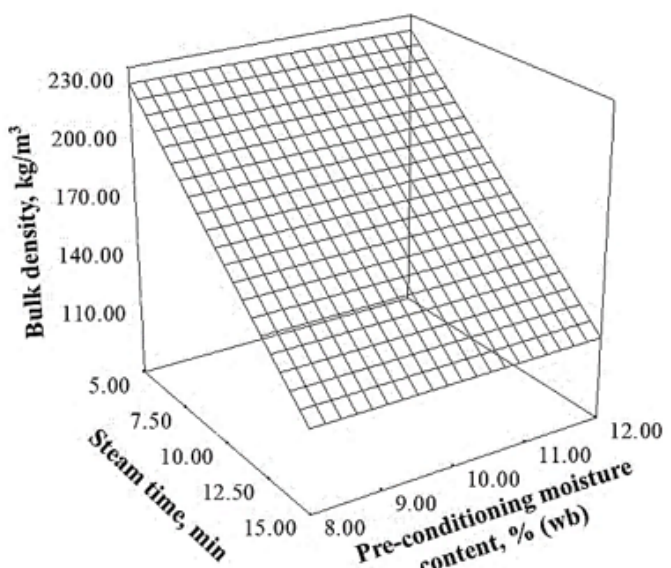

(b)

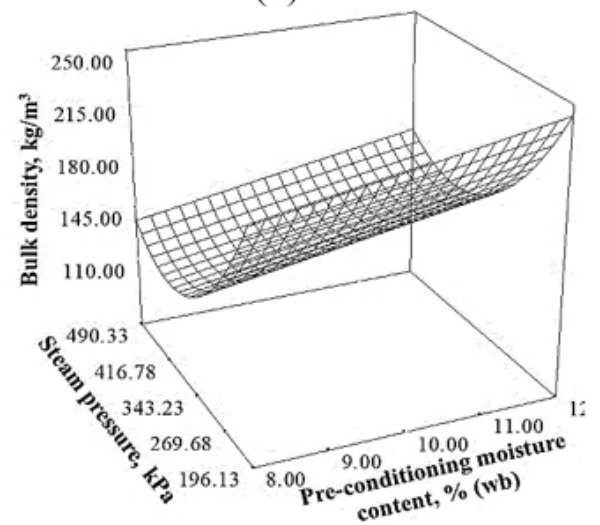

(d)

Figure 5: Bulk density of puffed brown rice under varied levels of steam pressure, time and preconditioned brown rice moisture content; ( $\mathrm{a} \& \mathrm{~b}$ ) microwave puffing, (c \& d) hot-sand-bed puffing 
Puffing of brown rice $\mid$ SI13

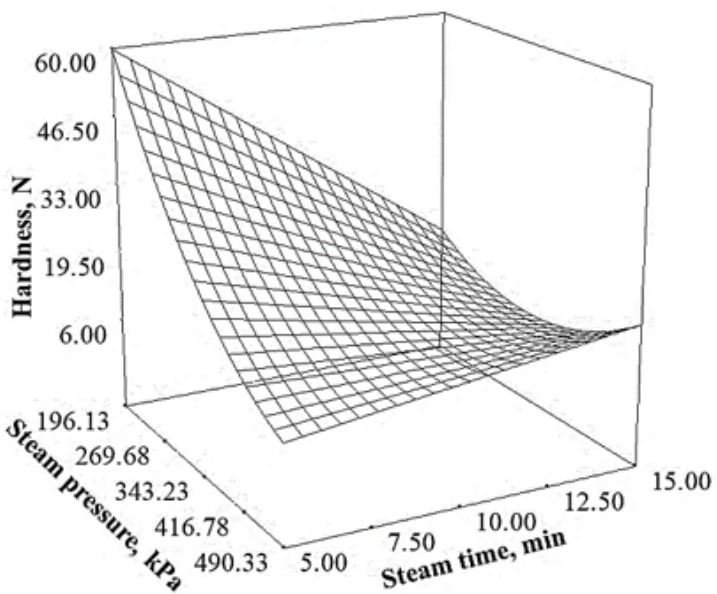

(a)

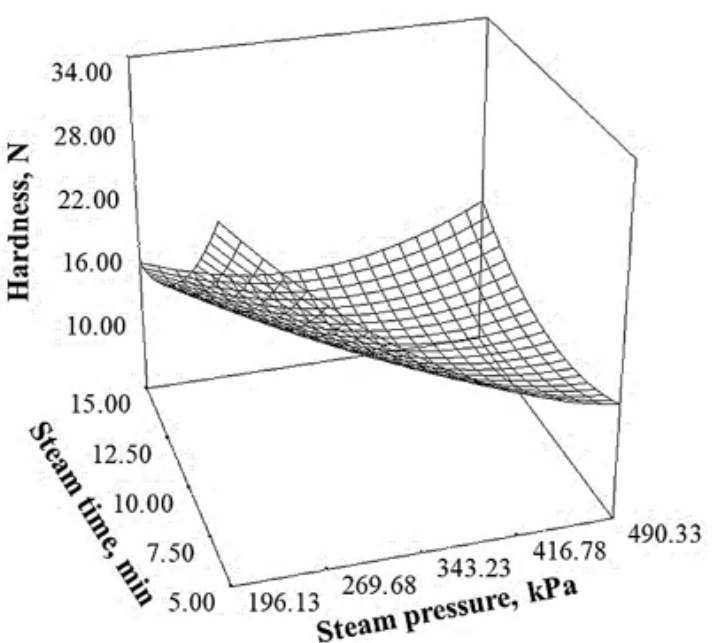

(c)

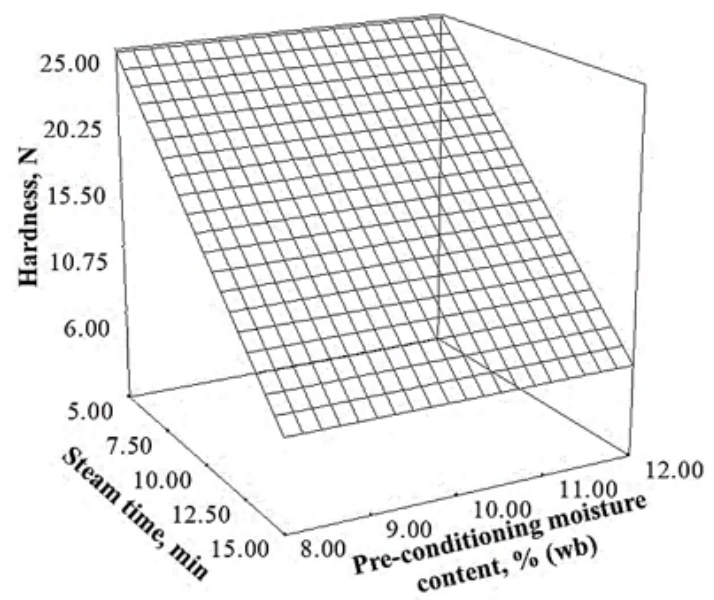

(b)

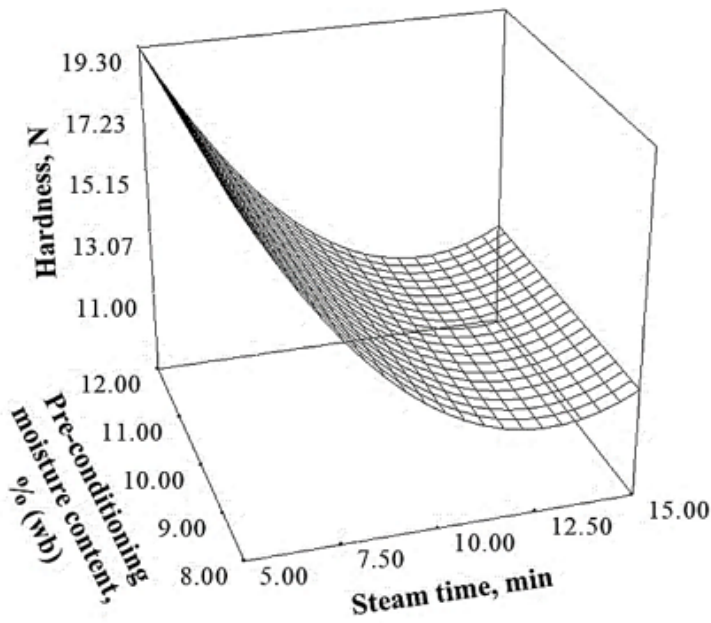

(d)

Figure 6: Hardness of puffed brown rice under varied levels of steaming pressure, time and preconditioned brown rice moisture content; (a \& b) microwave puffing, (c \& d) hot-sand-bed puffing 
Table 4: Validation of optimized puffing conditions

\begin{tabular}{|c|c|c|c|c|c|}
\hline Puffing method & Dependent variable & Predicted values & Actual values $\pm \mathrm{SD}$ & Mean difference & $\mathrm{p}$ - value (2 tailed) \\
\hline \multirow{5}{*}{ MW } & PP & 62.78 & $61.79 \pm 0.78$ & 0.99 & $0.091^{n s}$ \\
\hline & $\mathrm{ER}$ & 4.84 & $4.62 \pm 0.30$ & 0.22 & $0.287^{n s}$ \\
\hline & WI & 52.16 & $52.85 \pm 2.68$ & 0.68 & $0.680^{n s}$ \\
\hline & $\mathrm{BD}$ & 124.09 & $146.4 \pm 12.08$ & 22.27 & $0.033^{*}$ \\
\hline & $\mathrm{Hd}$ & 8.466 & $10.42 \pm 0.40$ & 1.95 & $0.001^{* * *}$ \\
\hline \multirow{4}{*}{ HSB } & ER & 6.45 & $6.055 \pm 0.10$ & 0.39 & $0.001^{* * *}$ \\
\hline & WI & 55.93 & $56.550 \pm 1.18$ & 0.61 & $0.410^{n s}$ \\
\hline & $\mathrm{BD}$ & 131.83 & $157.636 \pm 5.01$ & 25.80 & $0.001^{* * *}$ \\
\hline & $\mathrm{Hd}$ & 12.52 & $12.933 \pm 0.77$ & 0.41 & $0.371^{n s}$ \\
\hline
\end{tabular}

\subsection{Optimization}

Based on the highest D value, optimum conditions were selected. The ER and PP are essential quality characteristics for the puffed rice (Joshi et al., 2014). Emphasis was placed on ER and PP. Importance in the software system varied from $1(+)$ to $5(+++++)$ which represent least and most important, respectively. During the optimization of PP and ER, importance was set at four (software system for optimization) and WI, $\mathrm{BD}$ and Hd set on an importance of three or at default in the software for optimization. During the optimization PP, ER and WI were targeted at the maximum, and $\mathrm{Hd}$ and $\mathrm{BD}$ at the minimum. Optimum conditions obtained for microwave puffing were parboiling steam pressure of $303.6 \mathrm{kPa}$, steaming time of $14.25 \mathrm{~min}$ and pre-conditioned moisture content of $11.6 \%$ (wb). Corresponding optimum values of these parameters were $260.7 \mathrm{kPa}, 15 \mathrm{~min}$ and $8 \%$ (wb), respectively for brown rice puffing in the hot-sand-bed method.

Validation of these responses (mean of three) is presented in Table 4. The t-test was carried out for comparison between these responses to predict responses. The null hypothesis was that there will be no significant difference between the predicted and the experimental values. The Significant difference was found for BD $(\mathrm{p}<0.05)$ in both the puffing methods, Hd $(\mathrm{p}<0.001)$ for microwave puffing and ER $(\mathrm{p}<0.001)$ for hotsand-bed puffing. The mean difference was found to be satisfactory for all the dependent variables during validation (Table 4).

\section{Conclusions}

In this study, the effect of parboiling steaming pressure, time and pre-conditioned moisture content of brown rice was studied and optimized to achieve the highest quality puffed brown rice in the microwave and hot-sand-bed methods. The optimized parboiling steaming pressure, time and pre-conditioned moisture content for microwave were $303 \mathrm{kPa}, 14.25 \mathrm{~min}$ and 11.6 $\%$, respectively and these levels for hot-sand-bed puffing were $260.7 \mathrm{kPa}, 15 \mathrm{~min}$ and $8 \%$, respectively. Puffing characteristics of brown rice followed a quadratic relationship with processing parameters in both the puffing methods but WI follows a linear relationship. Parboiling steaming pressure and time were the only parameters affecting WI and Hd of puffed brown rice. More than $350 \mathrm{kPa}$ steaming pressure adversely affected the quality of the puffed brown rice.

Heating mediums used for puffing were found to have a substantial effect on the quality of the puffed brown rice. Optimum expansion of puffed brown rice in both puffing methods was obtained at $8 \%$ moisture level of the preconditioned brown rice. Although the brown rice puffing quality in the hot-sand-bed method was slightly better than in a microwave method, the microwave puffing process can replace hot-sandbed puffing to obtain a hygienic, fresh and uniform quality product. 


\section{References}

Agidi, G., Dauda, S. M., \& Igbeka, J. C. (2008). Effect of variety, pressure and specific volume of steam on the head rice yield of milled parboiled rice. Journal of Food Science and Technology-mysore, 45(3), 282283.

Ali, S. Z., \& Bhattacharya, K. R. (1982). Studies on pressure parboiling of rice. Journal of Food Science and Technology-mysore, 19(6), 236-242.

Bhattacharya, K. R. (2011). Rice quality: A guide to rice properties and analysis. Rice Quality: A Guide to Rice Properties and Analysis, 1-578.

Bhattacharya, S. (1996). Kinetics on colour changes in rice due to parboiling. Journal of Food Engineering, 29(1), 99-106. doi:10. 1016/0260-8774(95)00069-0

Chandrasekhar, P. R. (1989). Some studies on heated air fluidized bed puffing characteristics of rice (Doctoral dissertation, IIT, Kharagpur).

Chandrasekhar, P. R., \& Chattopadhyay, P. K. (1991). Rice puffing in relation to its varietal characteristics and processing conditions. Journal of Food Process Engineering, 14(4), 261-277. doi:10.1111/j.1745-4530. 1991.tb00136.x

Chinnaswamy, R., \& Bhattacharya, K. R. (1986). Pressure-parboiled rice-a new base for making expanded rice. Journal of Food Science and Technology-mysore, 23(1), 14-19.

Das, K. K. (2013). Fluidized bed pre-conditioning of rice and its microwave puffing (Doctoral dissertation, IIT Kharagpur).

Ekasilp, W., Soponronnarit, S., \& Therdyothin, A. (1995). Energy analysis in rice mills for cogeneration in thailand. Kasetsart J (Nat. Sci.) 29(1), 87-99.

Giri, S. K., \& Prasad, S. (2007). Optimization of microwave-vacuum drying of button mushrooms using response-surface methodology. Drying Technology, 25(4-6), 901-911. doi:10.1080/07373930701370407

Gul, K., Yousuf, B., Singh, A. K., Singh, P., \& Wani, A. A. (2015). Rice bran: Nutritional values and its emerging potential for development of functional food: A review.
Bioactive Carbohydrates and Dietary Fibre, 6, 24-30. doi:10.1016/j.bcdf.2015.06.002

Gulati, T., \& Datta, A. K. (2016). Coupled multiphase transport, large deformation and phase transition during rice puffing. Chemical Engineering Science, 139, 75-98. doi:10.1016/j.ces.2015.08.057

Hsu, C. L., Chen, W. L., Weng, Y. M., \& Tseng, C. Y. (2003). Chemical composition, physical properties, and antioxidant activities of yam flours as affected by different drying methods. Food Chemistry, 83(1), 8592. doi:10.1016/S0308-8146(03)00053-0

International Rice Research Institute. (2013). Standard evaluation system for rice, philippine, pp-125.

Joshi, N. D., Mohapatra, D., Joshi, D. C., \& Sutar, R. F. (2014). Puffing characteristics of parboiled milled rice in a domestic convective-microwave oven and process optimization. Food and Bioprocess Technology, 7(6), 1678-1688. doi:10.1007/s11947013-1220-7

Lamberts, L., Brijs, K., Mohamed, R., Verhelst, N., \& Delcour, J. A. (2006). Impact of browning reactions and bran pigments on color of parboiled rice. Journal of Agricultural and Food Chemistry, 54(26), 99249929. doi:10.1021/jf062140j

Lamberts, L., De Bie, E., Vandeputte, G. E., Veraverbeke, W. S., Derycke, V., De Man, W., \& Delcour, J. A. (2007). Effect of milling on colour and nutritional properties of rice. Food Chemistry, 100(4), 1496-1503. doi:10. 1016/j.foodchem.2005.11.042

Lamberts, L., Rombouts, I., Brijs, K., Gebruers, K., \& Delcour, J. A. (2008). Impact of parboiling conditions on maillard precursors and indicators in long-grain rice cultivars. Food Chemistry, 110(4), 916-922. doi:10. 1016/j.foodchem.2008.02.080

Mahanta, C. L., \& Bhattacharya, K. R. (2010). Relationship of starch changes to puffing expansion of parboiled rice. Journal of Food Science and Technology-mysore, 47(2), 182-187. doi:10.1007/s13197-0100038-9

Maisont, S., \& Narkrugsa, W. (2009). Effects of some physicochemical properties of paddy rice varieties on puffing qualities by 
microwave "original". Kasetsart JournalNatural Science, 43.

Maisont, S., \& Narkrugsa, W. (2010). Effects of salt, moisture content and microwave power on puffing qualities of puffed rice. Kasetsart Journal-Natural Science, 44.

Mariotti, M., Alamprese, C., Pagani, M. A., \& Lucisano, M. (2006). Effect of puffing on ultrastructure and physical characteristics of cereal grains and flours. Journal of $\mathrm{Ce}$ real Science, 43(1), 47-56. doi:10.1016/j. jcs.2005.06.007

Minati, M., \& Das, S. K. (2011). Effect of process parameters and optimization on microwave puffing performance of rice. Research Journal of Chemistry and Environment, 15(2), 454-461.

Mir, S. A., Bosco, S. J. D., Shah, M. A., \& Mir, M. M. (2016). Effect of puffing on physical and antioxidant properties of brown rice. Food Chemistry, 191, 139-146. doi:10. 1016/j.foodchem.2014.11.025

Mishra, G., Joshi, D. C., Mohapatra, D., \& Babu, V. B. (2015). Varietal influence on the microwave popping characteristics of sorghum. Journal of Cereal Science, 65, 1924. doi:10.1016/j.jcs.2015.06.001

Mohapatra, D., \& Bal, S. (2007). Effect of degree of milling on specific energy consumption, optical measurements and cooking quality of rice. Journal of Food Engineering, 80(1), 119-125. doi:10.1016/j.jfoodeng.2006.04. 055

Montgomery, D. C. (2017). Design and analysis of experiments. John Wiley \& sons.

Moraru, C., \& Kokini, J. (2006). Nucleation and expansion during extrusion and microwave heating of cereal foods. Comprehensive Reviews in Food Science and Food Safety, 2, 147-165. doi:10.1111/j.1541-4337. 2003. tb00020.x

Nath, A., Chattopadhyay, P. K., \& Majumdar, G. C. (2007). High temperature short time air puffed ready-to-eat (rte) potato snacks: Process parameter optimization. Journal of Food Engineering, 80(3), 770-780. doi:10. 1016/j.jfoodeng.2006.07.006

Official methods of analysis. Association of Official Analytical Chemists. (1990). Inc. washington, dc. 15th edn.
Roy, P., Ijiri, T., Okadome, H., Nei, D., Orikasa, T., Nakamura, N., \& Shiina, T. (2008). Effect of processing conditions on overall energy consumption and quality of rice (oryza sativa 1.) Journal of Food Engineering, 89(3), 343-348. doi:10.1016/j . jfoodeng.2008.05.015

Sharma, P., \& Gujral, H. S. (2011). Effect of sand roasting and microwave cooking on antioxidant activity of barley. Food Research International, 44(1), 235-240. doi:10.1016/j. foodres.2010.10.030

Shimoni, E., Dirks, E. M., \& Labuza, T. P. (2002). The relation between final popped volume of popcorn and thermal-physical parameters. Lebensmittel-wissenschaft Und-technologie-food Science and Technology, 35 (1), 93-98. doi:10.1006 / fstl. 2001. 0823

Smita, J. (2008). Development of a rice conditioner for making puffed rice using domestic microwave oven. Unpublished $M$. Tech thesis. Indian Institute of Technology Kharagpur, Kharagpur, West Bengal, India.

Swarnakar, A. K., Srivastav, P. P., \& Das, S. K. (2019). Optimization of preconditioning process of pressure parboiled brown rice (unpolished) for microwave puffing and its comparison with hot sand bed puffing. Journal of Food Process Engineering, 42(3). doi:10.1111/jfpe.13007

Swarnakar, A., Kalpana Devi, M., \& K. Das, S. (2014). Popping characteristic of paddy using microwave energy and optimization of process parameters. International Journal of Food Studies, 3. doi:10.7455/ijfs/3.1. 2014.a4

van der Sman, R. G. M., \& Bows, J. R. (2017). Critical factors in microwave expansion of starchy snacks. Journal of Food Engineering, 211, 69-84. doi:10.1016/j.jfoodeng. 2017.05.001 